\title{
PLANO DE AÇÃO HOSPITALAR: CONTRIBUIÇÃO DO PROGRAMA DE RESIDENCIA PROFISSIONAL EM ENFERMAGEM NA URGÊNCIA/TRAUMA ${ }^{1}$
}

\author{
HOSPITAL ACTION PLAN: CONTRIBUTION OF THE PROFESSIONAL \\ RESIDENCE IN NURSING IN URGENCY/TRAUMA
}

\author{
Lais Dornelles Machado², Vagner Costa Pereira ${ }^{3}$, Rosiane Filipin Rangel ${ }^{4}$, \\ Karine de Freitas Cáceres Machado ${ }^{5}$ Silomar Ilha ${ }^{6}$
}

\section{RESUMO}

A emergência é compreendida como uma condição de agravo à saúde, a qual implica em risco iminente de vida ou sofrimento intenso, exigindo, portanto, tratamento imediato. Para o atendimento nessa condição são utilizadas manobras denominadas como Suporte Básico de Vida (SBV) e Suporte Avançado de Vida (SAV). Sendo assim, o presente estudo tem como objetivo, relatar a experiência de uma residente na implementação de um plano de ação hospitalar, por meio da realização de oficinas de capacitação em SBV e SAV, com ênfase no código azul e na comunicação em alça fechada. Trata-se de um relato de experiência de uma residente do Programa de Residência Profissional em Enfermagem na Urgência/Trauma da Universidade Franciscana, acerca da construção e implementação de um plano de ação hospitalar, efetivado por meio de capacitações com foco na prática hospitalar e ênfase nas situações de emergência, durante o período de março a julho de 2019. Os resultados são apresentados em duas unidades: Construção de um plano de ação hospitalar pelos residentes em Enfermagem na Urgência e Trauma; Descrição das capacitações propostas pelo plano de ação hospitalar em 2019. Conclui-se que a implantação do plano de ação hospitalar agregou conhecimento prático e teórico as equipes de atuação das unidades hospitalares. Salienta-se que as ações do Plano, são parcerias profissionais acordadas entre o serviço e o Programa de residência, o que perpassa os residentes do ano corrente, pois se faz necessário seu seguimento.

Palavras-chave: Capacitação em serviço, Emergências, Enfermagem, Reanimação cardiopulmonar.

\section{ABSTRACT}

The emergency is understood as a condition of health problems, which implies an imminent risk of life or intense suffering, requiring, therefore, immediate treatment. To assist in this condition, maneuvers called Basic Life Support (BLS) and Advanced Life Support (FAS) are used. Therefore, the present study aims to report the experience of a resident in implementing a hospital action plan, through training workshops on

\footnotetext{
${ }^{1}$ Artigo derivado de Trabalho de Conclusão de Residência

${ }^{2}$ Enfermeira. Egressa do programa de Residência em Enfermagem na Urgência/Trauma - Universidade Franciscana. Santa Maria - RS, Brasil. E-mail: la_dornelles@hotmail.com

${ }^{3}$ Enfermeiro. Coordenador de Enfermagem e Responsável Técnico (RT) na Unidade de Pronto Atendimento - UPA 24h. Preceptor do Programa de Residência em Enfermagem na Urgência/Trauma. Santa Maria - RS, Brasil. E-mail: enfermagem.upa@sefas.org.br

${ }^{4}$ Enfermeira. Docente do curso de Enfermagem e tutora do Programa de Residência Profissional em Enfermagem na Urgência/Trauma - Universidade Franciscana. Santa Maria - RS, Brasil. E-mail: E-mail: rosianerangel@yahoo.com.br ${ }^{5}$ Enfermeira. Docente do curso de Enfermagem e tutora do Programa de Residência Profissional em Enfermagem na Urgência/Trauma - Universidade Franciscana. Santa Maria - RS, Brasil. E-mail: E-mail: karine@ufn.edu.br ${ }^{6}$ Orientador. Docente do curso de Enfermagem e coordenador do Programa de Residência Profissional em Enfermagem na Urgência/Trauma - Universidade Franciscana. Santa Maria - RS, Brasil. E-mail: silomar.ilha@unifra.br
} 
Basic Life Support and Advanced Life Support, with emphasis on blue code and closed loop communication. It is an experience report of a resident of the Nursing Professional Residency Program in Urgency / Trauma at the Franciscan University, about the construction and implementation of a hospital action plan carried out through training, focused on hospital practice and emphasis on emergency situations, during the period between March to July 2019. The results are presented in two units: construction of a hospital action plan by nursing residents in Urgency and Trauma; description of the training proposed by the hospital action plan in 2019. It is concluded that the implementation of the hospital action plan added practical and theoretical knowledge to the teams working in the hospital units. It should be noted that the actions of the Plan are professional partnerships agreed between the service and the Residency Program, which permeates the residents of the current year, as it is necessary to follow up.

Keywords: Inservice Training, Emergencies, Nursing, Cardiopulmonary Resuscitation.

\section{INTRODUÇÃO}

Ao considerar o perfil epidemiológico de morbimortalidade no Brasil, frequentemente se observa o aumento significativo de mortes por causas externas, principalmente traumas e violência (MELO; SÁ; SOBRINHO, 2016). Nesse sentido, o Ministério da Saúde (MS) com intuito de atender as necessidades da população nas situações de urgência ou emergência, reformulou a Política Nacional de Atenção às Urgências, implantada no ano de 2006 (BRASIL, 2006) e instituiu a Rede de Atenção às Urgências (RUE) no Sistema Único de Saúde (SUS), por meio da portaria no 1.600 de 7 de julho de 2011 (BRASIL, 2011).

A RUE tem como proposito, organizar o atendimento às urgências e emergências de forma a garantir acesso da população a esses serviços com uma assistência humanizada e integral (BRASIL, 2011). Para isso, se faz necessário reconhecer e distinguir as situações de urgência e emergência. A urgência é definida como uma condição grave, mas geralmente sem perigo iminente de falência de qualquer função vital. Já, a emergência é compreendida como uma condição de agravo à saúde, a qual implica em risco iminente de vida ou sofrimento intenso, exigindo, portanto, tratamento imediato (CFM, 1995).

Nesse contexto, houve a necessidade de mudanças no perfil dos profissionais que atuavam nas emergências, ampliando-se as propostas dos Programas de Residência Profissional e Multiprofissional em Saúde. Tais programas, constituem-se em um treinamento em serviço que possibilita, ao futuro especialista, a prática junto ao serviço de saúde. Tal vivência, possibilita que o profissional, na maioria das vezes, recém-formado, conheça a realidade dos processos de trabalho, assuma a supervisão de equipes de enfermagem e auxilie na resolução dos problemas cotidianos (ZANONI et al., 2015).

Nessa direção, no ano de 2014, por meio do edital no 32, de 24 de julho de 2014, foi aprovado o Programa de Residência Profissional em Enfermagem na Urgência/Trauma (BRASIL, 2014). Tal Programa, possui o objetivo geral de proporcionar aos profissionais enfermeiros conhecimentos específicos e qualificados sobre a assistência pré e intra-hospitalar de excelência em serviços de urgência, emergência e trauma (UFN, 2014). 
Os enfermeiros residentes são imediatamente inseridos na RUE do município em que o Programa está sediado e, desde logo, desafiados com proposições de melhorias nos cenários em que estão vinculados (BOTTEGA et al., 2019). Essa inserção permitiu, aos residentes, a compreensão da Parada Cardiorrespiratória (PCR) como uma das condições de maior gravidade e risco iminente à vida, pois caracteriza-se por uma condição em que ocorre a interrupção súbita da circulação sanguínea, culminando em perda da consciência, ausência de pulso e ausência de movimentos respiratórios ou respiração anormal, compreendida como gasping (AHA, 2016).

Diante disso, emergiu a proposta de um plano de ação, com vistas a capacitação dos profissionais atuantes no contexto hospitalar para o atendimento qualificado. $\mathrm{O}$ atendimento a essa condição de saúde ocorre por meio do Suporte Básico de Vida (SBV), o qual compreende um conjunto de técnicas sequenciais caracterizadas por compressões torácicas, abertura das vias aéreas, respiração artificial e desfibrilação. E, do Suporte Avançado de Vida (SAV), que consiste na manutenção do SBV, aliado à administração de medicamentos e o tratamento da causa da PCR (PENNA et al., 2016).

Para auxiliar nessa situação, pode ser empregado o código azul, compreendido como um protocolo realizado pelo Time de Resposta Rápida (TRR), composto por profissionais da área da saúde capacitados de acordo com a função que irão exercer no atendimento da PCR (BONIATTI, 2016). Além disso, é importante salientar a comunicação em alça fechado, a qual compreende a comunicação clara e objetiva, contemplada quando a mensagem vai do emissor para o receptor que, por sua vez, deve retornar indicando que a ouviu e a entendeu, realizando a tarefa solicitada e anunciando para o emissor, que a finalizou (KOCHHAN et al., 2015).

Assim, foram realizadas pelos Enfermeiros vinculados ao Programa de Residência Profissional em enfermagem na Urgência/Trauma, capacitações sobre SBV e SAV, com ênfase na utilização do código azul e da comunicação em alça fechada no ambiente hospitalar. As capacitações demonstraram potencial de promover o processo educativo dos profissionais, com vistas à sua autonomia e protagonismo em situações que requeiram atendimento de emergência. Por essa razão, devem ser socializadas com a comunidade acadêmica, fato que justifica a necessidade e relevância desse estudo.

Frente ao exposto, objetivou-se relatar a experiência dos Enfermeiros do Programa de Residência em Enfermagem na Urgência/Trauma na implementação do Plano de Ação Hospitalar, por meio da realização de oficinas de capacitação em SBV e SAV, com ênfase no código azul e na comunicação em alça fechada.

\section{MATERIAL E MÉTODOS}

Trata-se de um relato de experiência do Programa de Residência Profissional em Enfermagem na Urgência/Trauma da vinculado a Universidade Franciscana (UFN), acerca da construção e implementação 
de um plano de ação hospitalar, efetivado por meio de capacitações com foco na prática hospitalar e ênfase nas situações de emergência.

O Referido Programa de Residência, iniciou sus atividades no ano de 2015 e desde então conta com 12 vagas anuais, divididas em seis vagas semestrais, para enfermeiros que desejam se especializar em Urgência e Trauma. O processo seletivo ocorre por meio de concurso Público e o candidato aprovado nesse processo, mantêm vínculo de 24 meses junto ao Programa. Os residentes são denominados como R1, enquanto estão no seu primeiro ano de residência e, R2 durante o segundo ano. Durante esse período, os mesmos desenvolvem atividades junto a diversos serviços de saúde do município e tem entre as suas atribuições, a responsabilidade de colaborar para o bom funcionamento e melhorias necessárias nesses senários.

Dentre as propostas desenvolvidas pelos residentes, socializa-se, por meio desse relato, o plano de ação, o qual teve sua implantação no Hospital Casa de Saúde (HCS) situado na cidade de Santa Maria no interior do Rio Grande do Sul, Brasil. O referido hospital, é considerado de médio porte e conta com oito unidades assistenciais, contendo as especialidades: ginecologia, obstetrícia, mastologia, nefrologia, oftalmologia, ortopedia, pediatria, otorrinolaringologia, pneumologia, psiquiatria, urologia, nutrição, hematologia, gastroenterologia, cirurgia geral, psicologia, fonoaudiologia, clínica médica, dermatologia, angiologia e cirurgia vascular.

O HCS é utilizado como cenário de prática e de estágios para alunos do curso técnico de enfermagem, graduação em diversas áreas e para os Programas de Residência Profissional e Multiprofissional em saúde. Nesse relato constará o início da criação do plano de ação hospitalar que se deu no ano de 2018, e sua continuidade no ano corrente 2019. A construção do plano nos dois anos citados, aconteceu no momento da inserção dos residentes no campo de atuação na gestão da Unidade de Pronto Atendimento (UPA 24h), a qual está situada junto ao HCS.

As UPAs são consideradas o principal segmento fixo de urgência e emergência, definidas como unidade de média complexidade, fixadas entre a Atenção Primária em Saúde (APS) e o segmento de alta complexidade, a exemplo, dos hospitais de grande porte. São divididas em três níveis, denominados como portes, conforme a população referenciada, área física em que se encontra, número de leitos e de recursos humanos (BRASIL, 2011). A UPA/24, cenário desse estudo, está em funcionamento há sete anos, sendo administrada pela Associação Franciscana de Assistência à Saúde, através de um convênio com a Prefeitura da cidade de Santa Maria (SMS, 2019).

Encontra-se localizada em anexo ao HCS desde 2012, sendo a primeira UPA porte 3 do Estado do Rio Grande do Sul, com um alto número de atendimento/dia (SMS, 2019). A mesma vem sendo utilizada como campo de prática para os enfermeiros vinculados ao Programa de Residência Profissional em Enfermagem na Urgência/Trauma da UFN desde o ano de 2015. 


\section{RESULTADOS E DISCUSSÃO}

Os resultados desse relato, são didaticamente apresentados em duas unidades: Construção de um plano de ação hospitalar pelos residentes do Programa de Residência Profissional em Enfermagem na Urgência e Trauma; e, Descrição das capacitações propostas pelo plano de ação hospitalar em 2019.

\section{CONSTRUÇÃO DE UM PLANO DE AÇÃO HOSPITALAR PELOS RESIDENTES EM ENFERMAGEM NA URGÊNCIA E TRAUMA}

Os Programas de Residência Multiprofissional e em Área Profissional da Saúde instituídos pela portaria $\mathrm{n}^{0} 1.077$, de 12 de novembro de 2009 têm como proposta a formação a nível de pós-graduação lato sensu, uma especialização com carga horária de 60 horas semanais com duração de 2 anos, e dedicação exclusiva. Tem como objetivo, formar profissionais capazes de atuar no Sistema Único de Saúde (SUS) de forma crítica e reflexiva, aliando o conhecimento teórico a prática, e dessa forma a construção de espaços de saúde multidisciplinares, com foco na integração ensino-serviçocomunidade (BRASIL, 2009).

Ciente deste objetivo, no ano de 2018, a Coordenação de Ensino Pós Graduação do HCS solicitou à coordenação do Programa de Residência Profissional em Enfermagem na Urgência/Trauma a elaboração de um Plano de Ação, o qual deveria conter uma proposta de atividades anuais a serem realizadas pelos residentes no hospital, sendo este também apresentado por meio de relatório a cada final de ano à direção do HCS.

Com isso, a coordenação junto a terceira turma de residentes, compreendeu a pertinência da criação de ações que trouxessem melhorias a assistência de pacientes em situações de urgência/emergência no contexto hospitalar. Essa compreensão, foi fortalecida ainda, pela convicção de que a forma como é realizada a assistência ao paciente nesses momentos, implica diretamente na sua sobrevida, o que torna essencial a discussão de assuntos que cercam essa temática (AHA, 2016).

Dessa forma, os residentes definiram como estratégia de ação, a realização de capacitações aos profissionais dos serviços de saúde da UPA, com enfoque em temas que as equipes apresentavam dificuldades, como por exemplo, o SBV e SAV. Após o consentimento do preceptor, tutor e da coordenação, deram-se início os tramites legais. A residente que estava em atuação na gestão da UPA, elaborou um ofício informando a proposta das ações, contendo os conteúdos que seriam abordados nas capacitações, a forma de exposição, bem como o público alvo. Posteriormente, a residente elaborou um documento com as datas, horários e locais das capacitações e o fixou em murais da unidade para que os colaboradores pudessem ter acesso. 
O material foi abordado em slides para dar início ao embasamento teórico, com referência em protocolos de atendimento hospitalar atualizados e, para elucidar o conteúdo e as situações na prática, foi utilizado o simulador de RCP da UFN. O simulador caracteriza-se como um produto voltado para a fidelidade da experiência, à correspondência entre o que as pessoas experimentam e a realidade a qual está sendo simulada (REIS; GONÇALVES, 2014). A utilização do simulador, auxiliou na construção do conhecimento, pois proporcionou uma maior aproximação da realidade, durante as capacitações.

As capacitações ocorreram em dias previamente marcados, e se repetiram nos 3 turnos de serviço, como forma de alcançar o maior número de profissionais. Conforme a participação dos profissionais da UPA nas capacitações e a visibilidade das ações desenvolvidas dentro do HCS, os enfermeiros das unidades de internação começaram a demonstrar interesse e solicitar o agendamento das atividades em suas unidades por e-mail, visto que a demanda de atendimento em cada setor dificultava que os profissionais se deslocassem até a sala de reuniões da UPA.

Sendo assim, foi combinado com cada unidade o dia de capacitação em seu setor e, dessa forma, foi possível capacitar todas as unidades e atingir um grande número de profissionais do serviço. Ponto importante ressaltado pelas equipes, foi a oportunidade de discutir situações hipotéticas dentro do seu local de atuação, o que aproximou a atividade com a prática assistencial dos mesmos.

\section{DESCRIÇÃO DAS CAPACITAÇÕES PROPOSTAS PELO PLANO DE AÇÃO HOSPITALAR EM 2019}

No ano seguinte foi retomado o plano de ação e, junto ao preceptor do campo de atuação, a residente da gestão foi apresentada a enfermeira responsável técnica (RT) do HCS. Durante esse contato, foi possível estabelecer as atividades que seriam propostas pelo plano de ação hospitalar do Programa de Residência, referente ao ano de 2019.

Através desse encontro debateu-se a relevância do plano de ação anterior e ficou acordado um novo tema para as capacitações do ano corrente, que seria: Reanimação cardiopulmonar (RCP) Código azul e Comunicação em alça fechada. A RCP caracteriza-se por uma manobra realizada no atendimento em situações de PCR. Com o tema determinado, a residente da gestão elaborou um cronograma com as datas e horários propostos para a realização das capacitações, assim como os slides de apresentação. A partir disso, o plano de ação foi encaminhado ao preceptor do campo, a enfermeira RT, a Coordenadora de ensino de Pós-Graduação do HCS e ao coordenador do Programa de residência para aprovação.

Após o aceite de todos os responsáveis e feito as alterações solicitadas, a residente encaminhou o cronograma do Plano de Ação ao e-mail da Comissão de Controle de Infecção Hospitalar (CCIH) do HCS o qual ficou responsável por encaminhar as datas para as unidades. A residente, por sua vez, 
orientou o grupo dos residentes (R1 e R2), os quais fizeram parte das capacitações. Ficou estipulado que as capacitações iriam ser quinzenais, nos turnos tarde e noite.

As capacitações foram realizadas em sete unidades hospitalares que contemplavam as especialidades: Unidade clínica, cirúrgica, psiquiátrica e maternidade. Nas unidades clínicas, as capacitações foram realizadas pelos residentes nos dias 18/04/2019 e 16/05/2019; na unidade de internação cirúrgica e no centro cirúrgico, ocorreu nos dias 30/05/2019 e 09/07/2019; na unidade psiquiátrica, no dia 12/08/2019; e, na maternidade, no dia 14/08/2019. Participaram um total de 75 pessoas, dentre estes, profissionais do serviço, acadêmicos e residentes, sendo 10 da maternidade; 15 do centro cirúrgico; 17 da unidade psiquiátrica; 14 da unidade de internação cirúrgica e 19 das unidades clínicas.

$\mathrm{Na}$ chegada as unidades, os residentes conversavam com o enfermeiro de plantão, o qual organizava o ambiente para o desenvolvimento da capacitação em uma sala disponível na própria unidade. Após os profissionais eram convidados a participar de maneira voluntária das atividades. Com vistas a não deixar o setor desassistido, os profissionais foram acompanhados pelos residentes até o local das capacitações em duplas, enquanto os demais profissionais permaneciam no setor.

No momento da capacitação, por meio de um diálogo informal, os residentes questionavam se os profissionais já haviam atendido a uma situação de PCR e como o atendimento havia sido conduzido, momento que gerou a troca de experiências entre todos os participantes. A partir das experiências socializadas, os residentes explicavam aspectos relativos a como o atendimento poderia ter sido de forma mais tranquila e eficaz.

Na sequência, era apresentado um material preparado pelos residentes em slides, com base nos descritos da American Heart Association (AHA). Nesse momento, os profissionais eram estimulados a sempre que desejassem, questionar, contextualizar, socializar conhecimentos e tirar possíveis dúvidas. A AHA caracteriza-se como uma organização que tem como finalidade estabelecer protocolos e diretrizes no atendimento a RCP e ao atendimento cardiovascular de emergência (ACE), bem como a criação de vínculos com organizações de saúde, importantes no contexto mundial. Dessa forma, a AHA produz conteúdos atualizados para profissionais e demais interessados na área de saúde (AHA, 2016).

Após a apresentação, discussão e compreensão dos participantes, os residentes ofertavam a segunda parte da atividade, por meio da prática de uma PCR, com a utilização de um simulador. Assim, os participantes conduziam o atendimento de RCP, estimulados a utilizar os conhecimentos adquiridos durante a capacitação, sobre a PCR-RCP e sobre o código azul e a comunicação em alça fechada. Salienta-se que a interligação entre a teoria e a prática foi de vital importância para o aprendizado dos participantes, pois os mesmos puderam esclarecer dúvidas, atualizar conhecimentos que já haviam adquirido e treinar a sequência correta no simulador, bem como o trabalho em equipe. 
Nesse contexto, estudo que objetivou caracterizar a aprendizagem de estudantes de enfermagem e medicina a partir da inserção na prática profissional na primeira e segunda sério do curso, reforça a importância de aproximar o indivíduo do objeto de estudo, pois a proximidade com a prática faz com que as situações possam ser problematizadas e assim, estimular o pensamento crítico e ampliar o olhar do processo saúde-doença. Ainda, reflete sobre as dificuldades dessas ações nos espaços de saúde, e a necessidade da criação de movimentos que visem a inserção dos cursos de formação em saúde nos cenários de prática precocemente, como forma de promover a aprendizagem em grupo, corresponsabilização e construção compartilhada (NALOM et al., 2019).

Diante disso, ressalta-se a relevância do trabalho em equipe, o qual transforma atitudes centralizadoras e automáticas em um atendimento sociabilizado e humanizado, o que garante o bem-estar dos profissionais envolvidos e das pessoas assistidas. Quando a equipe atua em consonância, produz um trabalho objetivo, com coordenação, cooperação entre os colegas, onde as especificidades de cada trabalhador são valorizadas e agregadas ao conjunto, o que permite repensar as ações desenvolvidas diariamente no processo de trabalho (SILVA et al., 2018).

Após cada atividade, os residentes conversavam com os participantes buscando sanar algumas dúvidas que ainda pudessem existir; buscavam a reflexão de como os mesmos atuariam, a partir da capacitação, caso uma PCR ocorresse na sua unidade de atuação. Aproveitavam para avaliar a capacitação e estimular sugestões que os participantes sentissem necessidade e desejassem verbalizar. Alguns profissionais solicitaram o envio do material teórico utilizado durante a ação, o qual foi enviado aos mesmos, via e-mail, por uma das residentes.

A fala dos participantes das capacitações, demonstrou que os mesmos consideraram o momento de aprendizagem importante para as ações do dia a dia no trabalho. Citaram, que este tipo de capacitação pode ser ofertada no momento em que um novo colaborador entra no serviço, devido a rotatividade de profissionais ser alta, e na grande maioria recém-formados. Elencaram, ainda, que alguns temas abordados na fala dos residentes já eram de conhecimento, porém o conhecimento dos novos protocolos não era comum entre eles. Alguns desconheciam o uso de algumas medicações no protocolo de RCP, pois ainda faziam uso de medicações que foram retiradas da prática atual.

\section{CONSIDERAÇÕES FINAIS}

Considera-se que o objetivo desse estudo foi alcançado, pois foi possível relatar a experiência de uma residente na implementação do Plano de Ação Hospitalar, por meio da realização de oficinas de capacitação em SBV e SAV, com ênfase no código azul e na comunicação em alça fechada, no contexto hospitalar. 
Algumas fragilidades permearam as ações descritas, das quais salienta-se a dificuldade inicial em sensibilizar os profissionais para participarem. Contudo, tal fragilidade não impossibilitou a realização das ações descritas, pois os residentes se reorganizaram inúmeras vezes para a efetivação das mesmas.

Esse relato possibilitou evidenciar a importância da presença do residente como parte da equipe e como agente gestor do cuidado, onde a implantação de um Plano de Ação Hospitalar focado na RCP, com ênfase no código azul e na comunicação fechada, pode agregar conhecimento prático e teórico às equipes de atuação das unidades hospitalares. Os enfermeiros, técnicos de enfermagem, acadêmicos e residentes que participaram das ações foram desafiados a desenvolver seu pensamento crítico e compreender a relevância de suas ações frente ao cuidado dos pacientes atendidos, ao considerar a importância da comunicação interpessoal e o trabalho em equipe como primordial para atendimentos de qualidade.

Ao obter resultados positivos das atividades, tanto por relato verbal dos profissionais do serviço como da direção vigente, uma vez que possibilitou momentos de troca de saberes e instigou-se as equipes a fazerem o melhor possível, firmou-se o compromisso de continuidade das capacitações por meio dos planos de ação. Assim, salienta-se que as ações do Plano, são parcerias profissionais acordadas entre o serviço e o Programa de residência, o que perpassa os residentes do ano corrente, pois se faz necessário seu seguimento.

\section{REFERÊNCIAS}

\section{AMERICAN HEART ASSOCIATION (AHA). Advanced Cardiovascular Life Support Provider}

Manual. EUA: Integracolor, 2016.

BRASIL. Diário Oficial da União. Edital no 141, sexta-feira, 25 de julho de 2014. Brasília: 2014. Disponível em: https://bit.ly/2DhgLEt. Acesso em: dez. 2019.

BRASIL. Ministério da Educação. Portaria Interministerial n 1.077, de 12 de novembro de 2009. Diário Oficial da União no 217, de 13 de novembro de 2009 - Seção 1 - Pág. 7. Disponível em: https:// bit.ly/39SLG6c. Acesso em: dez. 2019.

BRASIL. Ministério da Saúde. Portaria no 1.600, de 7 de julho de 2011. Braspilia: 2011. Disponível em: https://bit.ly/3fwsKeJ. Acesso em: dez. 2019.

BRASIL. Ministério da Saúde. Política Nacional de Atenção às Urgências/Ministério da Saúde. 3. ed. ampl. - Brasília: Editora do Ministério da Saúde, 2006. 256 p. Disponível em: https://bit.ly/2EIf03z. Acesso em: dez. 2019. 
BOTTEGA, C. J. et al. Construção de um plano municipal de atenção às urgências: experiência empreendedora na enfermagem. In: BACKES, D.S.; ILHA, S.; COLOMÉ, J.S. Evidências Empreendedoras na Enfermagem: Ensino, Pesquisa e Extensão. Santa Maria: Universidade Franciscana - UFN, 2019. p. 242-256.

BONIATTI, M. M. Avanços na atuação, mais benefícios: as perspectivas dos times de resposta rápida. Revista Brasileira de Terapia Intensiva, v. 28, n. 3, p. 217-219, 2016. Disponível em: https://bit.ly/ 30pgBDT. Acesso em: julho, 2020.

CONSELHO FEDERAL DE MEDICINA (CFM). Resolução CFM no 1.451, de 10 de março de 1995. Brasília; 1995. Disponível em: https://bit.ly/33ozmJs. Acesso em: dez, 2019.

KOCHHAN, S. I.; et al. Parada cardiorrespiratória e manobras de ressuscitação na ótica de enfermeiros de um pronto socorro. Revista de Enfermagem da Universidade Federal do Piauí, v. 4, n. 1, p. 54-60, 2015. Disponível em: https://bit.ly/3hW4fJg. Acesso em: julho, 2020.

MELO, A. U. C.; SÀ, M.C.; SOBRINHO, J.R.P. Perfil epidemiológico da mortalidade por causas externas: uma análise da literatura no Brasil. Revista de Saúde UniAGES. Paripiranga, Bahia, Brasil. v. 1, n. 1, p. 9-32, 2016.

NALOM, D.M.F. et al. Health education: learning from professional practice. Ciência \& Saúde Coletiva, v.24, n.5, p. 1699- 1708, 2019. Disponível em: https://bit.ly/3hW4a8q. Acesso em: julho, 2020.

PENNA, G. H. et al. Manual de Medicina de Emergência. Rio de Janeiro: Atheneu, 2016

SECRETARIA DE MUNICÍPIO DA SAÚDE (SMS). UPA 24 horas completa 7 anos de parceria com a Prefeitura de Santa Maria. Prefeitura Municipal de Santa Maria, 2019. Disponível em: https://bit.ly/3fmdTmH. Acesso em: dez. 2019.

REIS, A.V.; GONÇALVES, B. S. Interfaces Tangíveis e Simuladores de Veículos: Avaliação do Honda Riding Trainer. Design \& Tecnologia, v.07, s.n., p.5, 2014. Disponível em: https://bit.ly/3gpFJA0. Acesso em: dez. 2019.

SILVA, K.R. et al. Trabalho em Equipe: reflexões dos gestores de serviços de urgência e emergência. Revista Médica de Minas Gerais, v. 28, n. Supl 5, p. e-S280501, 2018. Disponível em: http://rmmg. org/artigo/detalhes/2429. Acesso em: jul. 2020. 
UNIVERSIDADE FRANCISCANA (UFN). Projeto de Residência em Enfermagem na Urgência

e Trauma. Aprovado no Edital no 32, de 24 de julho de 2014. Disponível em: https://bit.ly/3gs97FU. Acesso em: dez. 2019.

ZANONI, C. S. et al. Contribuições da residência em enfermagem na atuação profissional de egressos.

Semina: Ciência Biológicas e da Saúde, v. 36, n. 1, p. 215-224, 2015. DOI: http://dx.doi.org/10.5433/ 1679-0367.2015v36n1Suplp215 
